\title{
Trainees' presentations
}

RECOGNISED BY THE COLLEGE

PUBLICATION OF ABSTRACTS FROM THE BEST REGIONAL PRESENTATIONS

\section{EAST MIDLANDS SURGICAL SOCIETY CORRESPONDENCE TO}

Mukul Dube, Honorary Secretary, East Midlands Surgical Society, King's Mill Hospital, Mansfield Road, Sutton in Ashfield, Nottinghamshire NG17 4JL, UK

E: mukul.dube@sfh-tr.nhs.uk

The following abstracts won prizes at the East Midlands Surgical Society meeting held on 8 November 2013 at Chesterfield Royal Hospital.

\section{Impaired endothelium dependent relaxation:} a proxy of viability for donation after circulatory death kidneys

G LEE, SA HOSGOOD, M PATEL, C CROTTY, K SHAH, ML NICHOLSON University Hospitals of Leicester NHS Trust, UK

CORRESPONDENCE TO

Gwyn Lee, E: gwynlee@hotmail.co.uk

\section{Introduction}

Donation after circulatory death (DCD) kidneys are at increased risk of delayed and primary non-function. This study investigated the endothelial response to acetylcholine with increasing cold time in a porcine DCD model. The response of a blood vessel to acetylcholine is the resultant of endothelially secreted nitric oxide and direct vasoconstrictive effects on smooth muscle.

\section{Methods}

Kidneys were harvested with 15 minutes of warm ischaemia and then underwent $2(n=7)$ or $16(n=8)$ hours of static cold storage. They were reperfused with a normothermic oxygenated autologous blood-based solution containing creatinine on an isolated organ perfusion circuit.

\section{Results}

The mean urine output (2h: $624 \mathrm{ml}$ [standard deviation (SD): $37 \mathrm{ml}$ ]; 16h: $335 \mathrm{ml}$ [SD: $164 \mathrm{ml}$ ]; $p=0.0014$ ) and creatinine clearance (2h: 12 [SD: 5.4ml/min/100g.h]; 16h: 5.1 [SD: $3.7 \mathrm{ml} / \mathrm{min} / 100 \mathrm{~g} . \mathrm{h}] ; p=0.0159)$ were higher in the $2 \mathrm{~h}$ group. Renal blood flow (2h: 441.3 [SD: $153.5 \mathrm{ml} / \mathrm{min} / 100 \mathrm{~g} . \mathrm{h}$ ]; 16h: 573 [SD: $255 \mathrm{ml} / \mathrm{min} / 100 \mathrm{~g} . \mathrm{h}$ ]; $p=0.244$ ) and intrarenal resistance (2h: 7.5 [SD: $2.8 \mathrm{mmHg} / \mathrm{min} / 100 \mathrm{~g}$ ]; 16h: 8.7 [SD: $8.2 \mathrm{mmHg} / \mathrm{min} / 100 \mathrm{~g}] ; p=0.714)$ were equivalent. There was a significant acetylcholine induced vasodilation in the $2 \mathrm{~h}$ (renal blood flow baseline 67.0 [SD: $26.2 \mathrm{ml} / \mathrm{min} / 100 \mathrm{~g}$ ] vs $10^{-8} \mathrm{mM}$ acetylcholine 81.2 [SD: $34.7 \mathrm{ml} / \mathrm{min} / 100 \mathrm{~g}$ ]; $p=0.0338$ ) but not the $16 \mathrm{~h}$ group $(p>0.05)$.

\section{Conclusions}

The reduction of function in the $16 \mathrm{~h}$ group may result from greater cold ischaemic injury. The loss of acetylcholine induced vasodilation after 16 hours of cold storage suggests that endothelium is more sensitive to cold ischaemia than vascular smooth muscle. Endothelial response to acetylcholine may form the basis for a test to determine viability of DCD kidneys after prolonged cold ischaemia.

\section{Effects of prolonged warm ischaemia in an experimental model of renal transplantation}

K SHAH, SA HOSGOOD, M PATEL, G LEE, C CROTTY, ML NICHOLSON

University Hospitals of Leicester NHS Trust, UK

CORRESPONDENCE TO

Keyur Shah, E: keyurkshah@gmail.com

\section{Introduction}

Persistent organ shortage remains a major obstacle in transplantation. Donation after circulatory death donors provide a large source of kidneys but most centres are reluctant to use uncontrolled DCD kidneys owing to prolonged warm ischaemic times. There are limited data on the tolerance of kidneys to prolonged warm ischaemia.

\section{Methods}

Porcine kidneys underwent 15, 60 and 90 minutes $(n=6,6,5$ respectively) of warm ischaemia and 2 hours of cold ischaemia followed by normothermic reperfusion with autologous blood for 3 hours. Various perfusion characteristics as well as markers of renal function and tubular injury were analysed. 


\section{Results}

Renal blood flow was significantly lower in the 60 and 90 (vs 15) minute groups at the start of reperfusion (17.3, 13.7 vs $29.4 \mathrm{ml} / \mathrm{min} / 100 \mathrm{~g} ; p=0.038$ ). However, the blood flow increased in all groups during reperfusion, more so in the 60 and 90 minute groups, and there was no difference between the groups from 30 minutes $(p=0.092)$ through to 3 hours $(p=0.731)$. Urine output (UO) and creatinine clearance $(\mathrm{CrCl})$ were significantly lower in the 90 minute group than in the 15 minute group (total UO $67 \mathrm{vs} 583 \mathrm{ml}$; $p=0.002 ; \mathrm{CrCl}$ area under curve 0.7 vs $11.4 \mathrm{ml} / \mathrm{min} / 100 \mathrm{~g}$; $p=0.002$ ). Notably, the UO in the 90 minute group improved during reperfusion and was significantly increased by the third hour compared with the first $(31 \mathrm{vs} 12 \mathrm{ml} / \mathrm{hr}$; $p=0.002$ ). Levels of urinary endothelin-1 were significantly higher in the 60 and 90 (vs 15) minute groups (35.7, 29.1 vs $17.3 \mathrm{pg} / \mathrm{ml} ; p=0.0014)$.

\section{Conclusions}

Prolonged warm ischaemia caused a significant degree of endothelial injury and loss of renal function. However, kidneys appeared to recover during reperfusion, suggesting that even after 90 minutes of warm ischaemia, the injury processes can be reversed. This has important implications for the potential use of uncontrolled DCD kidneys in transplantation. 